\title{
Optimization of growth temperature of multi-walled carbon nanotubes fabricated by chemical vapour deposition and their application for arsenic removal
}

\author{
S. Mageswari ${ }^{1}$, S. Kalaiselvan ${ }^{2}$, P.S. Syed Shabudeen ${ }^{3}$, \\ N. SIVAKUMAR ${ }^{4}$, S. KARTHIKEYAN ${ }^{4 *}$ \\ ${ }^{1}$ Department of Chemistry, Vivekanandha College of Engineering for Women, Tiruchengode, TN, India \\ ${ }^{2}$ Department of Chemistry, Hindustan College of Engineering, Coimbatore, TN, India \\ ${ }^{3}$ Department of Chemistry, Kumaraguru College of Technology, Coimbatore, TN, India \\ ${ }^{4}$ Department of Chemistry, Chikkanna Government Arts College, Tirupur, TN, India
}

\begin{abstract}
Multi-walled carbon nanotubes have been synthesized at different temperatures ranging from $550{ }^{\circ} \mathrm{C}$ to $750{ }^{\circ} \mathrm{C}$ on silica supported Fe-Mo catalyst by chemical vapour deposition technique using Cymbopogen flexuous oil under nitrogen atmosphere. The as-grown MWNTs were characterized by scanning electron microscope (SEM), high resolution transmission electron microscope (HRTEM), X-ray diffraction analysis (XRD) and Raman spectral studies. The HRTEM and Raman spectroscopic studies confirmed the evolution of MWNTs with the outer diameter between 20 and $40 \mathrm{~nm}$. The possibility of using as-grown MWNTs as an adsorbent for removal of As (V) ions from drinking water was studied. Adsorption isotherm data were interpreted by the Langmuir and Freundlich equations. Kinetic data were studied using Elovich, pseudo-first order and pseudo-second order equations in order to elucidate the reaction mechanism.
\end{abstract}

Keywords: spray pyrolysis; multi-walled carbon nanotubes; catalyst; As (V) ions; adsorption

(C) Wroclaw University of Technology.

\section{Introduction}

Carbon nanotubes (CNTs) are poised to make themselves the "materials of the millennium" due to their unique characteristics, such as good mechanical strength, good electrical conductivity and good aspect ratio [1]. Based on these properties, wide range of applications, such as electrically conducting plastics, transparent electrodes, flexible transistors, and field-emission displays has been extensively investigated. The most commonly used active catalyst for growing CNTs are magnetic elements, such as $\mathrm{Fe}, \mathrm{Co}$ or Ni. The elements have a strong tendency to agglomerate on the substrate at higher temperatures because of their magnetic properties and high specific surface energy [2, 3]. Other metal elements are added as stabilizers to prevent excessive agglomeration of the active

\footnotetext{
*E-mail:skmush@ rediffmail.com
}

elements. Molybdenum is one of the proven catalyst stabilizers for the growth of CNTs.

To date, several carbon precursors, such as methane, acetylene, benzene, xylene, toluene, etc., have been used as carbon precursors to synthesize carbon nanotubes [4]. These carbon precursors are related to fossil fuels, which may not be sufficiently available in near future. Therefore, in order to develop more competitive carbonaceous materials it is necessary to consider developing carbonaceous materials from the natural resources. There are few reports on the synthesis of CNTs from natural precursors, such as camphor [5], turpentine oil [6], eucalyptus oil [7], coconut oil [8], pine oil [9], helianthus annuus oil [10], jatropha curcas oil [11] and glycine $\max$ oil [12]. The significant advantages of the natural precursors are that they are very cheap, renewable, green and abundantly available.

CNTs have been proven to possess great potential as superior adsorbents for removing many 
kinds of organic and inorganic contaminants due to their large specific surface area, small size and capability to form both hollow, with high aspect ratio, and layered structures. Carbon nanotubes form aggregated pores due to the entanglement of hundreds of individual tubes that adhere to each other as a result of van der Waals forces of attraction [13].

Heavy metals, such as lead, arsenic, mercury etc., have been known for a long time to be serious water contaminants [14]. Arsenic is listed as a carcinogenic contaminant also responsible for other dangers to health, such as spontaneous miscarriage and diabetes. Porous carbon adsorption has been cited by the US environmental protection agency (EPA) as one of the best available environmental pollution control technologies [15].

In this article we report the synthesis of MWNTs using Cymbopogen flexuous oil being a natural source, which is renewable and cheap. The possibility of the use of MWNTs as an adsorbent for the removal As (V) ions and adsorption capacity of chosen adsorbents was studied at various influencing factors, such as temperature, $\mathrm{pH}$, time and dosage of adsorbent.

\section{Experimental methods}

\subsection{Synthesis of multi-walled carbon nanotubes}

A silica supported $\mathrm{Fe}-\mathrm{Mo}$ catalyst (Fe:Mo: $\mathrm{SiO}_{2}$ $=1: 0.1: 4)$ was prepared by wet impregnation method [16]. Appropriate quantities of metal salts (Merck), i.e. $\mathrm{Fe}\left(\mathrm{NO}_{3}\right)_{3} \cdot 6 \mathrm{H}_{2} \mathrm{O}$ and $\left(\mathrm{NH}_{4}\right)_{6} \mathrm{Mo}_{7} \mathrm{O}_{24} \cdot 4 \mathrm{H}_{2} \mathrm{O}$ were dissolved in methanol and mixed thoroughly with methanol suspension of silica (Merck). The solvent was then evaporated and the resultant cake heated to 90 to $100{ }^{\circ} \mathrm{C}$ for $3 \mathrm{~h}$, removed from the furnace and ground in an agate mortar. The fine powders were then calcined for $1 \mathrm{~h}$ at $450{ }^{\circ} \mathrm{C}$ and then re-ground before loading into the reactor. The prepared catalyst was directly placed in a quartz boat and kept at the centre of a quartz tube, which was placed inside a tubular furnace. The carrier gas nitrogen was introduced at a rate of $100 \mathrm{~mL} / \mathrm{min}$ into the quartz tube to remove any oxygen from there.
The temperature was raised from room temperature to the desired growth temperature. Subsequently, methyl ester of Cymbopogen flexuous oil was introduced into the quartz tube through a spray nozzle and the flow was maintained at a rate of $0.5 \mathrm{~mL} / \mathrm{min}$. The deposition was conducted for 30 min for each process at different temperatures from $550{ }^{\circ} \mathrm{C}$ to $750{ }^{\circ} \mathrm{C}$. Spray pyrolysis was carried out for 45 minutes and thereafter the furnace was cooled to room temperature. Nitrogen atmosphere was maintained throughout the experiment. The morphology and degree of graphitization of the as-grown nanostructures were characterized by scanning electron microscopy, (Hitachi SU6600), high resolution transmission electron microscopy (JEOL-3010), Raman spectroscopy (JASCO NRS$1500 \mathrm{~W}$, green laser with excitation wavelength 532 $\mathrm{nm}$ ) and thermo gravimetric analysis (TGA). Magnetic properties of the sample at room temperature were studied using a vibrating sample magnetometer. The as-grown products were subjected to purification process as follows [17]. The sample material was added to $5 \%$ HF solution to form an acidic slurry. This slurry was heated to $60^{\circ} \mathrm{C}$ and stirred at $600 \mathrm{rpm}$. The sample was filtered and washed with distilled water. The collected sample was dried at $120{ }^{\circ} \mathrm{C}$ in air for $2 \mathrm{~h}$. The stock solution of As (V) was prepared by dissolving $\mathrm{Na}_{2} \mathrm{HAsO}_{4} \cdot 7 \mathrm{H}_{2} \mathrm{O}$ in distilled water. The residual As (V) concentration in the solution after adsorption was analyzed using a flame atomic adsorption spectrometer (AAS). The solution $\mathrm{pH}$ was adjusted with $\mathrm{HCl}$ and $\mathrm{NaOH}$.

\subsection{Adsorption process}

As (V) adsorption capacity of MWNTs was determined in a batch reactor. The As (V) solutions of required concentration were prepared by diluting appropriate volume of a stock solution. The solution was further diluted to the required concentrations (10 to $100 \mathrm{mg} / \mathrm{L}$ ) before its use. The $\mathrm{pH}$ of the solutions was adjusted by adding $0.1 \mathrm{M} \mathrm{HNO}_{3}$ or $0.1 \mathrm{M} \mathrm{NaOH}$. All the experiments were performed by agitating $50 \mathrm{~mL}$ of the As (V) solution at the desired concentration and $50 \mathrm{mg}$ MWNTs in $100 \mathrm{~mL}$ bottles. Agitation was performed for a predetermined time at room temperature in a 
reciprocating shaker. The suspension was filtered through $0.45 \mu \mathrm{m}$ filters and the residual As (V) concentration was determined in the liquid phase using atomic absorption spectrometer (AAS, Shimadzu, Japan, model AA-6800). The percentage of adsorption was calculated using the relationship:

$$
R_{\%}=\frac{\left(C_{0}-C_{t}\right)}{C_{0}} \times 100
$$

where $\mathrm{C}_{0}$ and $\mathrm{C}_{t}$ are initial (inlet) and final concentrations of arsenic at time $t$. Then the amount of arsenic adsorption per unit mass of adsorbent at time $\mathrm{t}\left(\mathrm{q}_{t}\right)$ was calculated using the relationship:

$$
q_{t}=\frac{C_{0}-C_{t}}{W} \times V
$$

where $\mathrm{V}$ is the volume of solution $(\mathrm{L})$ and $\mathrm{W}$ is the mass of the adsorbent $(\mathrm{g})$.

\subsection{Effect of $\mathbf{p H}$ on the removal of As (V) ions}

The effect of $\mathrm{pH}$ on the adsorption of As (V) ions on MWNTs was investigated. The $\mathrm{pH}$ value played a vital role with respect to the adsorption of particular ions on MWNTs. The $\mathrm{pH}$ of solution affected the surface charge of the adsorbent and the degree of ionization. Fig. 1 shows that $\mathrm{pH}$ variation has some influence on the As (V) adsorption. In order to evaluate the effect of $\mathrm{pH}$ on the adsorption of As (V) on CNTs, a series of sample solutions containing As (V) at a concentration of $50 \mathrm{mg} / \mathrm{L}$ was adjusted to $\mathrm{pH}$ in the range of 2 to 10 with $0.1 \mathrm{~N} \mathrm{HNO}_{3}$ and $0.1 \mathrm{~N} \mathrm{NaOH}$ solutions. The $\mathrm{pH}$ of the solutions were measured by using an Elico pH meter (model L1-120-ISI, 1977). Fig. 1 shows that the adsorption of As $(\mathrm{V})$ decreases while there is an increase in the $\mathrm{pH}$ value. As (V) adsorption is strongly dependent on electrostatic parameters, such as adsorbent surface charge, which are dependent on $\mathrm{pH}$ [18].

The adsorption efficiency at $\mathrm{pH} 3$ was found to be $92.2 \%$. Therefore, in this study, the optimum $\mathrm{pH}$ value for As (V) adsorption was determined to be 3. The $\mathrm{pHzc}$ is the value of $\mathrm{pH}$, at which the surface of an adsorbent has a net neutral charge [19]. At higher $\mathrm{pH}$ values the surface has a net negative charge and at lower $\mathrm{pH}$ values the surface has

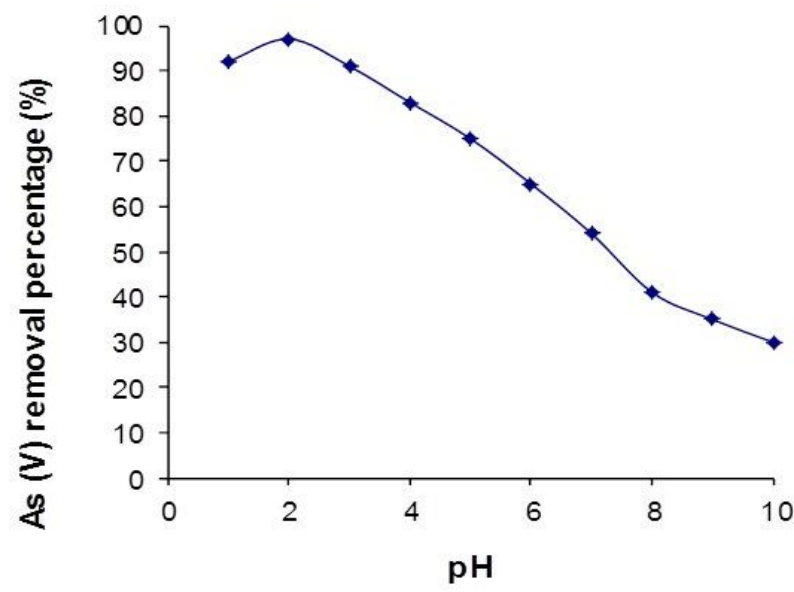

Fig. 1. Effect of $\mathrm{pH}$ on the adsorption of As (V) on to MWNTs at $650{ }^{\circ} \mathrm{C}$.

a net positive charge. As the $\mathrm{pH}$ of a system increases, the number of negatively charged sites increases [20]. A negatively charged surface site on the adsorbent does not favor the adsorption of As (V) ions due to the electrostatic repulsion. The isoelectric point value of 6.4 for MWNTs indicates that the surface of MWNTs is positively charged under acidic conditions and the positive charges facilitate the removal of As (V) ions.

\subsection{Result and discussion}

Fig. 2 explicitly presents the SEM images of MWNTs grown at various temperatures. Fig. 2a shows that the formation of MWNTs is low at $550{ }^{\circ} \mathrm{C}$ because at this temperature carbon decomposes partially leading to the carbonaceous materials. At $650{ }^{\circ} \mathrm{C}$, as the temperature was suitable for complete pyrolysis of carbon sources, pyrolysed carbon atoms diffused over the catalyst particles and helped to initiate the growth of nanotubes, so that it was possible to obtain uniform diameters in the grown MWNTs, Fig. $2 \mathrm{~b}$. At $750{ }^{\circ} \mathrm{C}$ the quantity of MWNTs decreased and thick nanotubes were formed. The diameter of nanotubes increased with increasing the temperature.

The HRTEM images in Fig. 3 illustrate the small amount of amorphous carbon present in the MWNTs with the diameters of ca. $30 \mathrm{~nm}$ at $550{ }^{\circ} \mathrm{C}$. At $650{ }^{\circ} \mathrm{C}$, the MWNTs have tubular structure with the inner and outer diameters making a uniform 
structure over the entire length of the tube. The overall diameter of MWNTs has been found to be $\approx 35 \mathrm{~nm}$ at $650{ }^{\circ} \mathrm{C}$ and $\sim 40 \mathrm{~nm}$ at $750{ }^{\circ} \mathrm{C}$. It is clearly seen that the diameter of the MWNTs increases significantly with increasing temperature.

The results of Raman spectroscopy analysis in Fig. 4 represent the MWNTs grown on the catalyst surface at $650{ }^{\circ} \mathrm{C}$, indicating two characteristic peaks at $1346 \mathrm{~cm}^{-1}$ and $1576 \mathrm{~cm}^{-1}$, which correspond to $\mathrm{D}$ and $\mathrm{G}$ bands, respectively. The $\mathrm{G}$ bands are related to stretching vibration in the basal plane of graphite crystal, which have been normalized to the same intensity. The D bands are associated with the disordered or defective planar graphite structure. The D peaks at $1346 \mathrm{~cm}^{-1}$ can be attributed to the defects in the curved graphene sheets. Therefore, the Raman spectrum provides a definite evidence that the MWNTs have graphitic structure.

Fig. 5 shows XRD pattern of MWNTs crystal structure obtained by X-ray diffraction method. The peaks are indexed as the (002) and (101) reflections of hexagonal graphite. Intense peaks found at $26.35^{\circ}$ and $44.44^{\circ}$ can be indexed to the (002) and (101) planes, respectively.

\section{Adsorption isotherm}

The experimental data for As (V) adsorption onto MWNTs could be evaluated by the Langmuir and Freundlich isotherm models:

$$
\begin{gathered}
Q=\frac{Q_{0} b C_{e}}{1+Q_{0} C_{e}} \\
Q=K_{F} C_{e}{ }^{n}
\end{gathered}
$$

where $\mathrm{C}_{e}$ is the equilibrium concentration of As (V) $(\mathrm{mg} / \mathrm{L}), \mathrm{Q}_{0}\left(\mathrm{mg} \cdot \mathrm{g}^{-1}\right)$ and $\mathrm{b}\left(\mathrm{L} \cdot \mathrm{mg}^{-1}\right)$ are Langmuir constants and $\mathrm{K}_{F}\left(\mathrm{mg} \cdot \mathrm{g}^{-1}\right)$ and $\mathrm{n}$ are Freundlich constants. The constants of Langmuir and Freundlich models are obtained from fitting the adsorption equilibrium data and are listed in Table 1. The correlation coefficients of Langmuir and Freundlich models are 0.993 and 0.967 , respectively, indicating that the Langmuir model is more appropriate to describe the adsorption characteristics of As $(\mathrm{V})$ onto the chosen adsorbent.

\subsection{Kinetics of adsorption}

Adsorption kinetics is used to investigate the mechanism and rate controlling steps of adsorption. Kinetics data obtained are then applied to different models to describe the interaction between As (V) and chosen adsorbents. Pseudo-first order, pseudo-second order and Elovich kinetic models were used to elucidate the complex dynamics of adsorption process. To determine the equation that best describes the adsorption of As (V), a standard error of estimate was calculated for each kinetic equation, viz. pseudo first order, pseudo second order and Elovich equation. A relatively high value of regression coefficient $\left(\mathrm{R}^{2}\right)$ was used as the criterium for the best fit [21]:

$$
R^{2}=\frac{\sum q^{2}-\sum\left(q-q^{\prime}\right)^{2}}{\sum q^{2}}
$$

where $\mathrm{q}$ and $\mathrm{q}^{\prime}$ are measured and calculated amounts of As (V) adsorbed on a chosen adsorbent at time $\mathrm{t}$.

\subsubsection{Pseudo-first order kinetic model}

The pseudo first order equation [22] is generally expressed as first order rate expression as shown below.

$$
\frac{d q_{t}}{d_{t}}=k_{1}\left(q_{e}-q_{t}\right)
$$

where $\mathrm{q}_{e}$ and $\mathrm{q}_{t}$ are adsorption capacities $\left(\mathrm{mg} \cdot \mathrm{g}^{-1}\right.$ ) at equilibrium and at time $\mathrm{t}$, respectively, $\mathrm{k}_{1}$ is the rate constant of pseudo-first order adsorption $\left(\min ^{-1}\right)$.

\subsubsection{Pseudo-second order kinetic model}

The pseudo-second order equation [23] has been considered for describing adsorption of As (V) on chosen adsorbates. The linearized form of the pseudo-second order rate equation is given as:

$$
\frac{t}{q_{t}}=\frac{1}{k_{2} q_{e}^{2}}+\frac{t}{q_{e}}
$$

where $\mathrm{k}_{2}$ is the rate constant of pseudo second order adsorption $\left(\mathrm{g} \cdot \mathrm{mg}^{-1} \cdot \mathrm{min}^{-1}\right), \mathrm{q}_{e}$ and $\mathrm{q}_{t}$ are the values of the amount of As (V) adsorbed per unit mass of adsorbate at equilibrium and at any time t, respectively. 

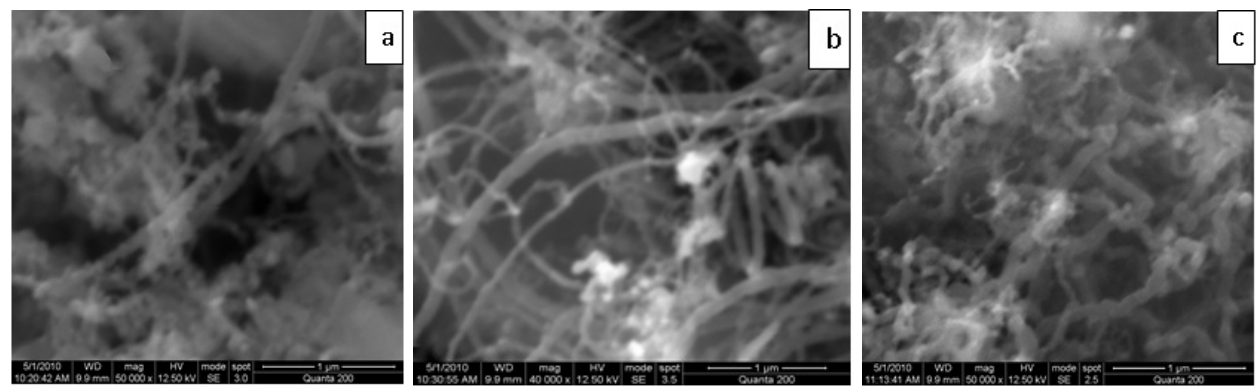

Fig. 2. SEM images of MWNTs grown on Fe-Mo catalyst supported on silica at various temperatures: (a) $550{ }^{\circ} \mathrm{C}$, (b) $650{ }^{\circ} \mathrm{C}$, and (c) $750{ }^{\circ} \mathrm{C}$.
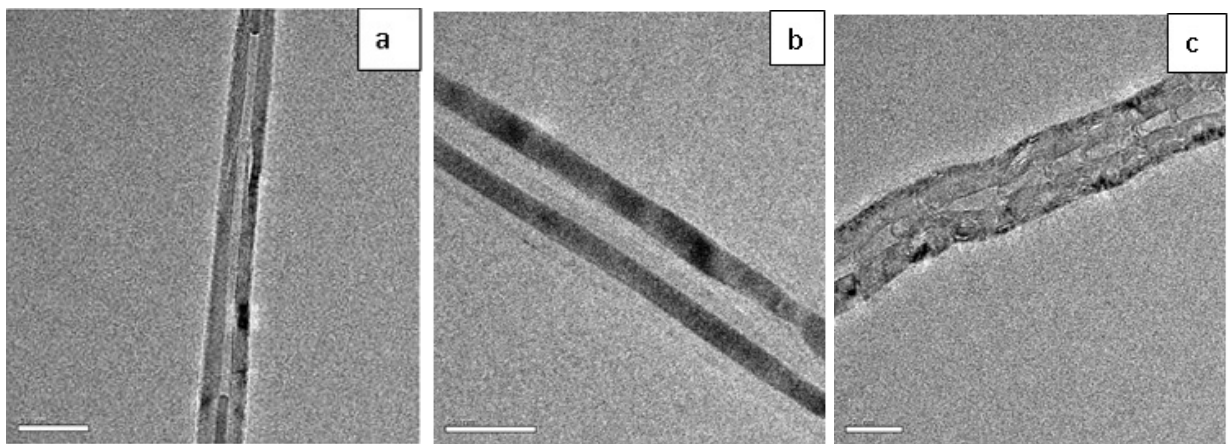

Fig. 3. TEM images of MWNTs grown on Fe-Mo catalyst supported on silica at various temperatures (a) $550{ }^{\circ} \mathrm{C}$, (b) $650{ }^{\circ} \mathrm{C}$, and (c) $750{ }^{\circ} \mathrm{C}$.

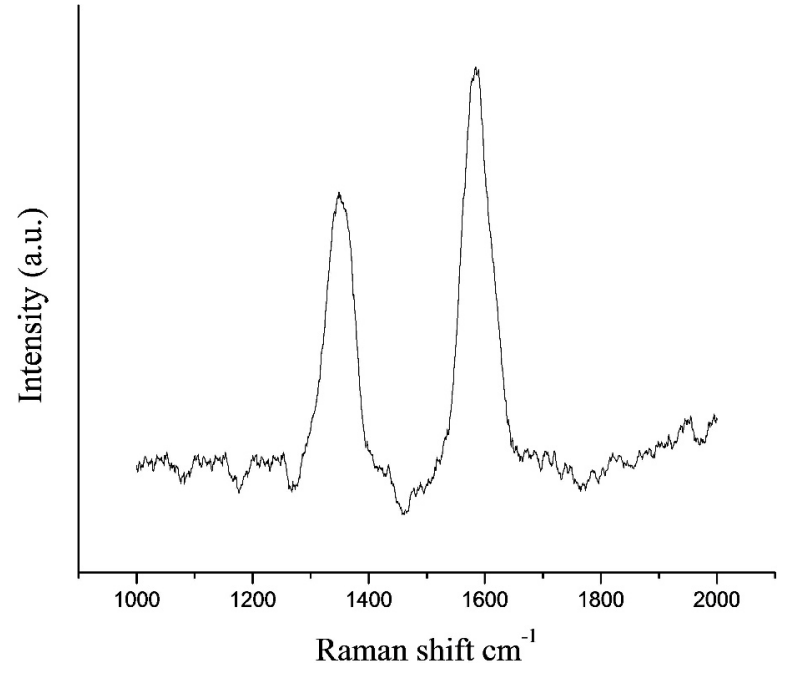

Fig. 4. Typical Raman spectrum of the MWNTs grown at $650{ }^{\circ} \mathrm{C}$.

\subsubsection{Elovich model}

Elovich equation is another kinetic model used to describe adsorption of As (V) on chosen solid

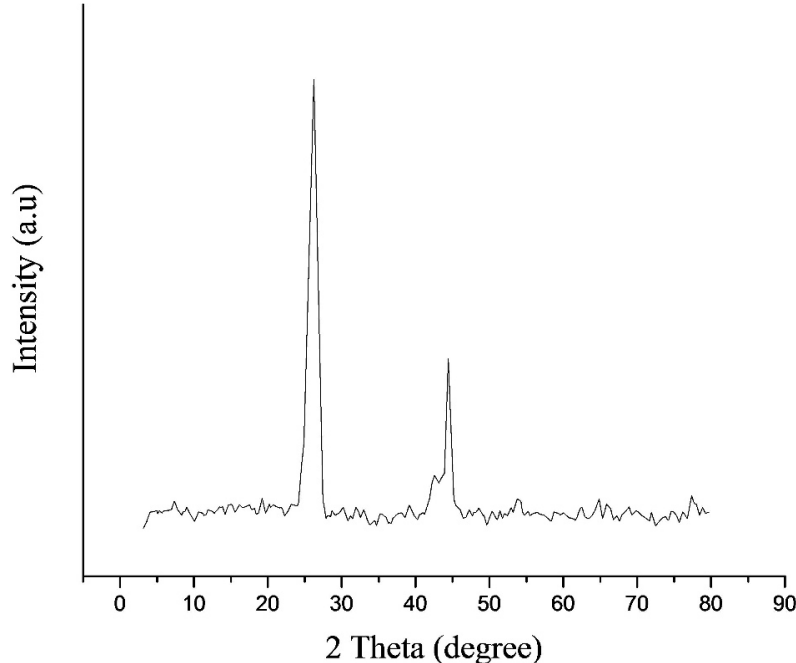

Fig. 5. XRD pattern of MWNTs grown at $650{ }^{\circ} \mathrm{C}$.

adsorbents. The equation [21] is generally expressed by:

$$
\frac{d q_{t}}{d_{t}}=\alpha e^{-\beta q_{t}}
$$


Table 1. Langmuir and Freundlich models for adsorption of As (V) onto purified chosen MWNTs.

\begin{tabular}{ccccccc}
\hline \multirow{2}{*}{ Adsorption isotherm models } & \multicolumn{3}{c}{ Langmuir models } & \multicolumn{4}{c}{ Freundlich models } \\
\cline { 2 - 7 } & $\mathrm{Q}_{0}\left(\mathrm{mg} \cdot \mathrm{g}^{-1}\right)$ & $\mathrm{b}\left(\mathrm{L} \cdot \mathrm{mg}^{-1}\right)$ & $\mathrm{R}^{2}$ & $\mathrm{~K}_{F}\left(\mathrm{mg} \cdot \mathrm{g}^{-1}\right)$ & $\mathrm{n}$ & $\mathrm{R}^{2}$ \\
\hline \hline As (V) & 32.68 & 0.22 & 0.993 & 11.84 & 0.244 & 0.967 \\
\hline
\end{tabular}

where $\alpha$ and $\beta$ are Elovich coefficients that represent the initial adsorption rate $\left(\mathrm{mg} \cdot \mathrm{g}^{-1} \cdot \mathrm{min}^{-1}\right)$ and the desorption constant $\left(\mathrm{g} \cdot \mathrm{mg}^{-1}\right)$, respectively.

\subsection{Batch adsorption studies}

All reagents used were of AR grade (E Merck). $50 \mathrm{~mL}$ of $\mathrm{pH}$ adjusted arsenic solution of a known concentration $\left(\mathrm{C}_{0}\right)$ was taken in a $100 \mathrm{~mL}$ screwcap conical flask with a required amount of adsorbent and was agitated at a speed of $200 \mathrm{rpm}$ in a thermostatic shaker bath at $27^{\circ} \mathrm{C}$ for a specified period of time. Then the solution was filtered through a $0.45 \mu \mathrm{m}$ membrane filter.

\subsection{Effect of adsorbent dosage on As (V) adsorption}

The effect of MWNTs dose in the range of $1 \mathrm{~g} / \mathrm{L}$ to $10 \mathrm{~g} / \mathrm{L}$ on As $(\mathrm{V})$ adsorption was investigated at $\mathrm{pH}$ 3. The initial As $(\mathrm{V})$ concentration was kept constant at $50 \mathrm{mg} / \mathrm{L}$ and the contact time used was 2.5 h. Fig. 6 shows that the As (V) adsorption increased from $37 \%$ to $80 \%$ when the adsorbent dose increased from $1 \mathrm{~g} / \mathrm{L}$ to $10 \mathrm{~g} / \mathrm{L}$. The adsorption capacity decreased from $17.7 \mathrm{mg} / \mathrm{g}$ to $3.9 \mathrm{mg} / \mathrm{g}$. The increase in percentage of As (V) adsorption with the increase of adsorbent dose may be due to increased number of available adsorption sites and the decrease in adsorption capacity is mainly due to unsaturation of adsorption sites through adsorption reaction.

\subsection{Effect of temperature on kinetic rate constant and rate parameters}

Adsorption experiments were carried out with a fixed initial As (V) concentration $(50 \mathrm{mg} / \mathrm{L})$ at $\mathrm{pH} 3$ and at different temperatures, viz. $30{ }^{\circ} \mathrm{C}$, $45^{\circ} \mathrm{C}$ and $60{ }^{\circ} \mathrm{C}$. The analysis of the data collected in Table 2 reveals that the increase in temperature upon As (V) removal has a significant effect on the pseudo first order and Elovich rate constants. The

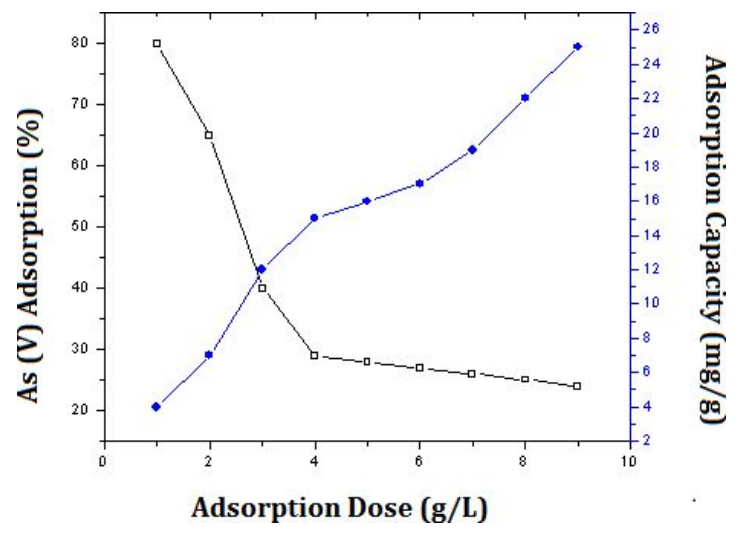

Fig. 6. Effect of adsorbent dose on As (V) adsorption.

results reveal also that the influence of temperature on pseudo second order rate constant is appreciable. The value of correlation coefficient $R^{2}(0.992)$ for pseudo second order rate equation shows that the adsorption of As (V) ions by MWNTs was better than that obtained with Elovich rate equation.

\subsection{Thermodynamic parameters}

The thermodynamic parameters obtained for the chosen adsorbent-adsorbate system were calculated using the following equations [24]:

$$
\begin{gathered}
K_{c}-\frac{C_{A e}}{C_{e}} \\
\Delta G=-R T \ln K_{c} \\
\log K_{c}=\frac{\Delta S}{2.303 R}-\frac{\Delta H}{2.303 R T}
\end{gathered}
$$

$\mathrm{K}_{c}$ is equilibrium constant, $\mathrm{C}_{A e}$ is the solid phase concentration at equilibrium, $\mathrm{C}_{e}$ is residual concentration at equilibrium, $\mathrm{R}$ is gas constant $\left(\mathrm{J} \cdot \mathrm{mol}^{-1}\right)$ and $\mathrm{T}$ is the temperature in Kelvin, $\Delta \mathrm{G}$ is Gibbs free energy $\left(\mathrm{kJ} \cdot \mathrm{mol}^{-1}\right), \Delta \mathrm{H}$ is enthalpy change $\left(\mathrm{kJ} \cdot \mathrm{mol}^{-1}\right)$ and $\Delta \mathrm{S}$ is entropy change $\left(\mathrm{kJ} \cdot \mathrm{mol}^{-1}\right)$. 
Table 2. Adsorption kinetic model rate constants for chosen MWNTs at different temperatures.

\begin{tabular}{|c|c|c|c|c|c|c|c|c|c|}
\hline \multirow{3}{*}{ Adsorbent } & \multirow{3}{*}{$\begin{array}{c}\text { Initial } \\
\text { temperature }\end{array}$} & \multicolumn{2}{|c|}{ Pseudo first order } & \multicolumn{4}{|c|}{ Pseudo second order } & \multicolumn{2}{|c|}{ Elovich model } \\
\hline & & $\mathrm{K}_{1}$ & $\mathrm{R}^{2}$ & $\mathrm{~K}_{2}$ & $\mathrm{~h}$ & $\mathrm{R}^{2}$ & $\alpha$ & $\beta$ & $\mathrm{R}^{2}$ \\
\hline & & $\left(\min ^{-1}\right)$ & & $\left(\mathrm{g} \cdot \mathrm{mg}^{-1} \cdot \mathrm{m}\right.$ & $\mathrm{g}^{-1} \cdot \min ^{-1}$ & & $g$ & $\left(\mathrm{~g} \cdot \mathrm{mg}^{-1}\right.$ & \\
\hline \multirow{3}{*}{ MWNTs } & $35^{\circ} \mathrm{C}$ & 0.132 & 0.914 & 0.122 & 21.615 & 0.988 & 103.70 & 0.214 & 0.927 \\
\hline & $45^{\circ} \mathrm{C}$ & 0.136 & 0.916 & 0.012 & 14.210 & 0.992 & 114.15 & 0.136 & 0.957 \\
\hline & $60{ }^{\circ} \mathrm{C}$ & 0.169 & 0.921 & 0.124 & 11.229 & 0.988 & 124.55 & 0.328 & 0.937 \\
\hline
\end{tabular}

$\Delta \mathrm{H}$ and $\Delta \mathrm{S}$ were obtained from the slope and intercept of van't Hoff plot $\left(1 / \mathrm{t}\right.$ vs. $\left.\operatorname{lnK}_{c}\right)$ and their values are presented in Table 3 . The negative values of free energy change $(\Delta \mathrm{G})$ indicate feasibility and spontaneous nature of adsorption. The positive value of $\Delta S$ is due to the increased randomness during the adsorption and positive $\Delta \mathrm{H}$ value indicates endothermic nature of adsorption.

\subsection{Mechanism of As (V) adsorption onto MWNTs}

The high correlation coefficients were obtained using pseudo first order, pseudo second order and Elovich kinetic models. It seems to be impossible to identify, which adsorption mechanism actually played the most important role.

In adsorption process of As (V) on a solid surface, the As $(\mathrm{V})$ species migrate towards the surface of the adsorbent. This type of migration proceeds until the concentration of the adsorbate species on the surface of the adsorbent reaches maximum. Once equilibrium is attained, the migration of the solute species from the solution stops. In this situation, it is possible to measure the magnitude of distribution of the solute species at the solid-liquid interface. The magnitude of this kind of distribution is a measure of efficiency of the chosen adsorbent and adsorbate species.

When MWNTs are in contact with a solution containing As (V), the metal ions first migrate from the bulk solution to the surface of the liquid film. This surface exerts a diffusion barrier, which may be noteworthy. The involvement of a significant quantum of diffusion barrier indicates a dominant role of the film diffusion in the adsorption process. Furthermore, the rate of adsorption process is controlled either by external diffusion, internal diffusion or by both types of diffusion.

The adsorption of an adsorbent on MWNTs is remarkably different from adsorption on other conventional porous carbons in several aspects. First, due to their one-dimensional nanostructure, the external surface available for adsorption is considerably larger than the surface area arising from inner cavities. The predominance of outer cavity to inner cavity surface area determines the adsorption characteristics of As (V) on MWNTs. The adsorption on the external surface of MWNTs is more important than the adsorption inside the micro/mesoporous cavities. Another noteworthy difference can be ascribed to the interstitial space between individual nanotubes. The dimension of this space is determined by the relative positions among individual tubular structures.

In the batch mode contact time adsorption experiments, rapid stirring was maintained. This made As (V) migrate from the solution to the external surface of the adsorbent material and this step controlled the rate of the adsorption process [25]. To interpret the experimental data it is necessary to recognize the steps involved in the process of adsorption that govern the overall rate of As (V) removal. The mathematical treatments recommended by Boyd et al. have been applied [26]. These mathematical treatments were found to be useful to distinguish between particles diffusion and film diffusion.

The successive steps in the adsorption of As (V) by adsorbents include:

(I) Transport of adsorbates to the external surface of adsorbent (film diffusion);

(II) Transport of the adsorbates within the pores of the adsorbent except for a small amount 
Table 3. Thermodynamic parameters for As (V) on chosen MWNTs.

\begin{tabular}{cccccc}
\hline \multirow{2}{*}{ Adsorbent } & \multicolumn{3}{c}{$\Delta \mathrm{G} \times 10^{4}\left(\mathrm{~kJ} \cdot \mathrm{mol}^{-1}\right)$} & \multirow{2}{*}{$\left(\mathrm{kJ} \cdot \mathrm{mol}^{-1}\right)$} & $\Delta \mathrm{S}\left(\mathrm{kJ} \cdot \mathrm{mol}^{-1}\right)$ \\
\cline { 2 - 5 } & $35{ }^{\circ} \mathrm{C}$ & $45{ }^{\circ} \mathrm{C}$ & $60{ }^{\circ} \mathrm{C}$ & & \\
\hline \hline MWNTs & -11.79 & -10.74 & -10.20 & 13.12 & 431.85 \\
\hline
\end{tabular}

of adsorption, which occurs on the external surface (particle diffusion);

(III) Adsorptions of the ingoing ion (adsorbate) on the interior surface of the adsorbent.

Only the third process can be considered as not limiting step in the uptake of As (V) onto MWNTs [27]. The remaining two steps impart the following three possibilities:

Case I: external transport $<$ internal transport if the rate is governed by particle diffusion.

Case II: external transport > internal transport if the rate is governed by external diffusion.

Case III:external transport $\approx$ internal transport if the transport of adsorbate ions to the boundary is not possible at a reasonable rate; this may result in formation of a liquid film surrounded by the adsorbent particles with a proper concentration gradient.

As rapid stirring was maintained in the study, the transport of the adsorbed species, As (V), from the solution to the pores of the adsorbent material might control the rate of adsorption process. Hence, the author concludes that the mechanism of As $(\mathrm{V})$ removal by the chosen adsorbents is complex. It indicates the probable occurrence of both film diffusion and intraparticle diffusion. Therefore, the adsorption data were further analyzed by the kinetic expression given by Boyd et al.:

$$
\begin{gathered}
F=\frac{q_{t}}{q_{e}}=1-\frac{6}{\pi^{2}} \sum_{N-1}^{\alpha} \frac{1}{n^{2}} \exp \left[\frac{-D_{i t} \pi^{2} n^{2}}{r^{2}}\right] \\
B_{t}=\frac{\pi^{2} D_{i}}{r^{2}}
\end{gathered}
$$

In the present study, the quantitative treatment of the sorption dynamic was found in accordance with the observation made by Reichenberg [28], as described by the following equation:

$$
F=1-\frac{6}{\pi^{2}} \sum_{N-1}^{\alpha} \frac{1}{n^{2} \exp \left[-n^{2} \beta_{t}\right]}
$$

where $\mathrm{F}$ is the fractional attainment of equilibrium at time $t$ and $n$ is a constant [29]:

$$
F=\frac{Q_{t}}{Q_{\infty}}
$$

where $\mathrm{Q}_{t}$ and $\mathrm{Q}_{\infty}$ are the amounts adsorbed after time $t$ and after infinite time, respectively:

$$
B=\frac{\pi^{2} D_{i}}{r_{0}^{2}}=\text { time constant }
$$

where $\mathrm{D}_{i}$ is the effective diffusion coefficient of adsorbate in the adsorbent phase and $r_{0}$ is the radius of adsorbent particles.

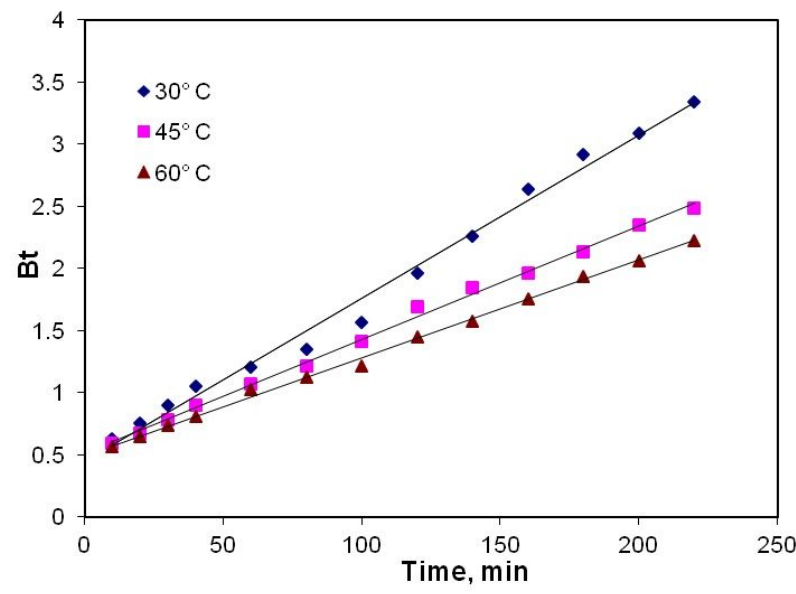

Fig. 7. $\mathrm{B}_{t}$ vs. time plots of $\mathrm{As}(\mathrm{V})$ adsorbed on MWNTs obtained from Cymbopogen flexuous oil at $650{ }^{\circ} \mathrm{C}$.

For every observed value of $\mathrm{F}$, corresponding values of $\mathrm{B}_{t}$ were derived from Reichenberg's table. In each case, the plot of $\mathrm{B}_{t}$ vs. time distinguishes between the processes involved in film diffusion and particles-diffusion, controlling the rate of adsorption. 
Table 4. Effective diffusion coefficient $\left(\mathrm{D}_{i}\right)$ pre exponential constant $\left(\mathrm{D}_{0}\right)$ activation energy $($ Ea) and entropy of activation for diffusion of As (V) in chosen MWNTS.

\begin{tabular}{ccccccc}
\hline \multirow{2}{*}{ Adsorbent } & \multicolumn{3}{c}{$\mathrm{D}_{i}\left(\mathrm{~m}^{2} / \mathrm{s}\right)$} & \multirow{2}{*}{$\mathrm{D}_{0}\left(\mathrm{~m}^{2} / \mathrm{s}\right)$} & \multirow{2}{*}{$\mathrm{E}_{a}(\mathrm{~kJ} / \mathrm{mol}) \Delta \mathrm{S}^{\#}\left(\mathrm{~kJ}^{-1} \cdot \mathrm{mol}^{-1}\right)$} \\
\cline { 2 - 5 } & $30{ }^{\circ} \mathrm{C}$ & $45^{\circ} \mathrm{C}$ & $60^{\circ} \mathrm{C}$ & & & \\
\hline \hline MWNTs & $3.22 \times 10^{-13}$ & $7.13 \times 10^{-13}$ & $9.41 \times 10^{-14}$ & $4.94 \times 10^{-4}$ & 22.42 & -51.62 \\
\hline
\end{tabular}

Typical $\mathrm{B}_{t}$ vs. time plots at the concentration of $20 \mathrm{mg} / \mathrm{L} \mathrm{As}(\mathrm{V})$ adsorbed on MWNTs at different temperatures are presented in Fig. 7. The $\mathrm{B}_{t}$ vs. time plots for the adsorption of As (V) adsorbed on MWNTs were found to be linear at the temperatures of 30,45 and $60^{\circ} \mathrm{C}$, thus, the process involved can be considered as film diffusion. At $30{ }^{\circ} \mathrm{C}$ the adsorbent exhibits linearity in $\mathrm{B}_{t}$ vs. time plots in the entire concentration range, but the straight lines obtained do not pass through the origin, revealing thereby that the rate-determining process is film diffusion at this temperature for the chosen adsorbent.

The $\mathrm{D}_{i}$ values were also calculated for each adsorbent material at the temperatures of 30,45 and $60{ }^{\circ} \mathrm{C}$ using equation 10 , and the obtained values indicate that $\mathrm{D}_{i}$ increases with an increase in temperature. This may be due to the increased mobility of ions and decreased retarding forces acting on diffusing ion. The calculated values of activation energy Ea, entropy of activation $\Delta \mathrm{S}^{\#}$, and preexponential constant $\left(D_{0}\right)$, analogous to the Arrhenius frequency factor, do not show any significant change in the internal structure of MWNTs during the adsorption, as it is shown below:

$$
\begin{gathered}
D_{i}=D_{0} \exp \left[-E_{a} / R T\right] \\
D_{0}=\left(2.72 d^{2} k T / h\right) \exp \left[\Delta S^{\#} / R\right]
\end{gathered}
$$

where $\mathrm{d}$ is the average distance between the successive exchange sites and is taken as $5 \AA$ and $\mathrm{R}$, $\mathrm{h}$ and $\mathrm{k}$ are the gas, Planck and Boltzmann constants, respectively. The values of $\mathrm{E}_{a}, \mathrm{D}_{i}, \mathrm{D}_{0}, \Delta \mathrm{S}^{\#}$ and other parameters are given in the Table 4 . The negative values of $\Delta S^{\#}$ indicate that no significant change occurs in the internal structure of chosen adsorbents during the adsorption process.

\section{Conclusions}

Multi-walled carbon nanotubes were obtained by chemical vapour deposition technique using Cymbopogen flexuous oil, an unconventional natural precursor. The experimental diameter of CNTs was found to be about 20 to $40 \mathrm{~nm}$ and the achieved yield was $60 \%$ at $650{ }^{\circ} \mathrm{C}$, confirming the possibility and reliability of obtaining MWNTs as a major adsorbent source to be applied in the process of eliminating As (V) from aqueous solution. Furthermore, the adsorption of As (V) was found to be dependent on $\mathrm{pH}$, temperature and dosage of the adsorbent. Thermodynamic parameters obtained for the adsorbents account for feasibility of the process at each concentration of As (V). The kinetics study also revealed that elimination of As (V) takes place through a film diffusion process at all the concentrations and temperatures of MWNTs obtained from Cymbopogen flexuous oil. The saturation percentage was found to be $93 \%$ for the MWNTs and the As (V) adsorption on adsorbent was found to follow the pseudo second-order rate equations. Furthermore, this research can be scaled up for mass production of MWNTs for multiple benefits.

\section{References}

[1] LU J.P., Phys. Rev. Lett, 79 (1997), 1297.

[2] Chen B., Wu P., Carbon, 43(15) (2005), 3172.

[3] Kumar M., Ando., J. Nanosci. Nanotechnol, 10 (2010), 3739.

[4] Sadeghian Z., New Carbon Mater, 24(1) (2009), 33.

[5] Kumar M., Ando Y., J. Chem. Phys. Letter, 374 (5 6) (2003), 521.

[6] Afre R. A., Soga T., Jimbo T., Kumar M., Ando Y., Sharon M., Chem. Phys. Lett, 414 (2005), 6.

[7] Ghose P., Afre R.A., Soga T., Jimbo T., Mater. Lett, 61 (2007), 3786.

[8] Paul S., Samdarshi S. K., New Carbon Mater, 26 (2) (2011), 85.

[9] Karthikeyan S., Mahalingam P., Inter. J. Nanotechnol. Appl, 4(3) (2010), 189. 
[10] Karthikeyan S., Angulakshmi V.S., J. Environ. Nanotechnol, 1(1) (2012) 40.

[11] Karthikeyan S., Mahalingam P., Inter. J. Green Nanotechnol. Phys. Chem, 2(2) (2010), 39.

[12] Karthikeyan S., Angulakshmi V.S., SathiskuMAR C., KARTHIK M., J.Environ. Nanotechnol, 2 (1) (2013), 101.

[13] FEZA GeyIKÇI., Fullerenes, Nanotubes Carbon Nanostruct, 21 (2013), 579.

[14] Bassam S. Tawabini, Salman F. Al-Khaldi, Mazen M. Khaled, J.Environ. Sci. Health., Part A, 46 (2011), 215.

[15] Debyshire F., Jagtoyan Andrews R., Rao A., Martin Gullon I., Grulke E., Chem. Phys. Carbon, 27 (2001), 1.

[16] Mhlanga S. D., Kartick C. M., Robin C., Michael J. W., Neil J. C. S., Afr. J. Chem., 62 (2009), 67.

[17] Engel-Herbert R., Pforte H., Hesjedal T., Mater. Lett, 61 (2007), 2589.

[18] Rao G.P., Lu C., Su F., Appl. Nanotechnol. Sep. Purif., 58 (2007), 224.

[19] HIscock K., Hydrogeology Principles and Practice. Black well publishing, 2005.
[20] FeZA GeyiKci., Fullerenes, Nanotubes, And Carbon Nanostructures, 21 (2013), 579.

[21] Chien S.H., Clayton W.R., Soil sci. Soc. Am. J, 44 (1980), 265.

[22] LAgERGREN S., Kungliga Svenska VetenskapsakaDemiens Handlingar, 24 (4) (1898), 139.

[23] Ho Y.S., John-Wase D.A., Forster C.F., Adsorption Sci. Technol, 18 (2000), 639.

[24] Stephen Inbaraj B., Sulochana N., Indian J. Chem. Technol., 9 (2002), 201.

[25] Weber Jr W. J., Morris J. C., J. Sanit. Eng. Div. Am. Soc. Civ. En, 89 (1963), 31.

[26] Boyd G.E., Adamson A.W., Meyers JR L.S., J. Am. Chem. Soc, 69 (1947), 2836.

[27] Bhattacharya A. K., Venkobachar C., Adsorpt. J. Environ. Eng. Div. ASCE, 110 (1984), 110.

[28] Reichenberg D., J. Am. Chem. Soc, 75 (1953), 589.

[29] Gupta V. K., Ali I., J. Colloid interface Sci, 271 (2004), 321.

Received 2013-08-15

Accepted 2014-08-12 